\title{
Mitochondrial ATP synthase: architecture, function and pathology
}

\author{
An I. Jonckheere • Jan A. M. Smeitink • \\ Richard J. T. Rodenburg
}

Received: 20 May 2011 /Revised: 22 July 2011 / Accepted: 27 July 2011 / Published online: 27 August 2011

(C) The Author(s) 2011. This article is published with open access at Springerlink.com

\begin{abstract}
Human mitochondrial (mt) ATP synthase, or complex $\mathrm{V}$ consists of two functional domains: $\mathrm{F}_{1}$, situated in the mitochondrial matrix, and $\mathrm{F}_{\mathrm{o}}$, located in the inner mitochondrial membrane. Complex $\mathrm{V}$ uses the energy created by the proton electrochemical gradient to phosphorylate ADP to ATP. This review covers the architecture, function and assembly of complex V. The role of complex $\mathrm{V}$ di-and oligomerization and its relation with mitochondrial morphology is discussed. Finally, pathology related to complex V deficiency and current therapeutic strategies are highlighted. Despite the huge progress in this research field over the past decades, questions remain to be answered regarding the structure of subunits, the function of the rotary nanomotor at a molecular level, and the human complex $\mathrm{V}$ assembly process. The elucidation of more nuclear genetic defects will guide physio(patho)logical studies, paving the way for future therapeutic interventions.
\end{abstract}

Mitochondrial ATP production is the main energy source for intracellular metabolic pathways (Schapira 2006). The human mitochondrial (mt) ATP synthase, or complex V (EC 3.6.3.14) is the 5th multi subunit oxidative phosphorylation (OXPHOS) complex. It synthesizes ATP from ADP in the mitochondrial matrix using the energy provided by the proton electrochemical gradient (Capaldi et al. 1994;

Communicated by: Ertan Mayatepek

Competing interest: None declared.

A. I. Jonckheere · J. A. M. Smeitink • R. J. T. Rodenburg $(\bowtie)$

Department of Pediatrics, Nijmegen Center for Mitochondrial

Disorders, 656 Laboratory for Genetic, Endocrine, and Metabolic

Disorders, Radboud University Nijmegen Medical Center,

PO Box 9101, 6500 HB Nijmegen, The Netherlands

e-mail: r.rodenburg@cukz.umcn.nl
Nijtmans et al. 1995; Zeviani and Di Donato 2004). To date, numerous mutations in the mtDNA encoded subunits $\mathrm{a}$ and $\mathrm{A} 6 \mathrm{~L}$ have been found, next to mutations in a structural subunit (subunit epsilon, (Mayr et al. 2010)), an assembly factor (ATP12, (De Meirleir et al. 2004)) and an ancillary factor (TMEM70, (Cizkova et al. 2008)) which are nuclear-encoded. Most of these mutations give rise to severe mitochondrial disease phenotypes, ranging from NARP (Neuropathy, Ataxia, and Retinitis Pigmentosa) or

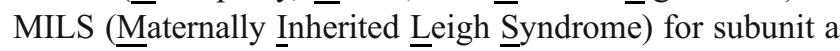
mutations to neonatal mitochondrial encephalo(cardio)myopathy and dysmorphic features in patients with an ATP12 or TMEM70 gene mutation (De Meirleir et al. 2004; Cizkova et al. 2008). In this article, we have aimed to review the 5th OXPHOS complex with respect to architecture, function, assembly, pathology, current therapeutic options and future perspectives. The structure and, intriguingly, the oligomerization of complex $\mathrm{V}$ determine its function, the former by the so-called "rotary catalysis" (Devenish et al. 2008) and the latter by influencing mitochondrial and cristae morphology (Strauss et al. 2008), as will be discussed below.

\section{ATP synthase: architecture (Fig. 1)}

ATP synthase consists of two well defined protein entities: the $F_{1}$ sector, a soluble portion situated in the mitochondrial matrix, and the $F_{o}$ sector, bound to the inner mitochondrial membrane. $F_{1}$ is composed of three copies of each of subunits $\alpha$ and $\beta$, and one each of subunits $\gamma, \delta$ and $\varepsilon$. $F_{1}$ subunits $\gamma, \delta$ and $\varepsilon$ constitute the central stalk of complex $\mathrm{V}$. $\mathrm{F}_{\mathrm{o}}$ consists of a subunit c-ring (probably comprising eight copies, as shown in bovine mitochondria (Watt et al. 2010)) and one copy each of subunits a, b, d, $F_{6}$ and the 


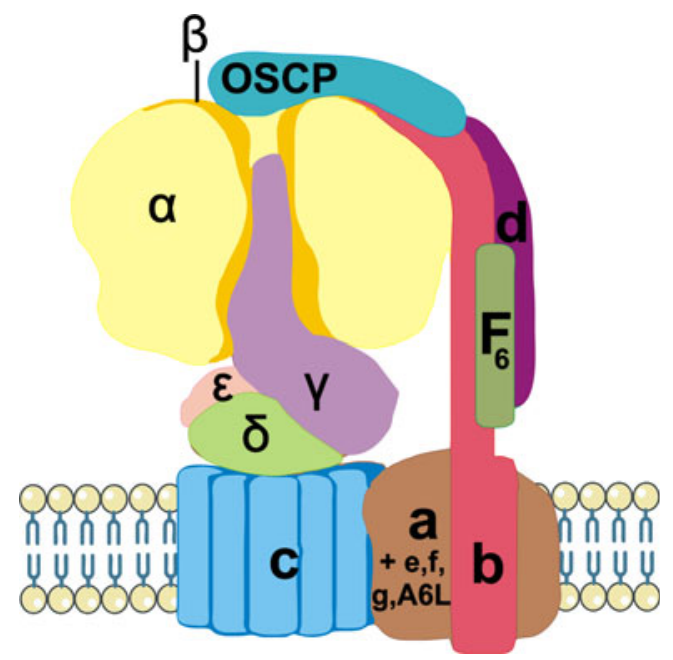

Fig. 1 Human mitochondrial ATP synthase, or complex V, consists of two functional domains, $\mathrm{F}_{1}$ and $\mathrm{F}_{\mathrm{o}}$. $\mathrm{F}_{1}$ comprises 5 different subunits (three $\alpha$, three $\beta$, and one $\gamma, \delta$ and $\varepsilon$ ) and is situated in the mitochondrial matrix. $\mathrm{F}_{\mathrm{o}}$ contains subunits $\mathrm{c}, \mathrm{a}, \mathrm{b}, \mathrm{d}, \mathrm{F}_{6}$, OSCP and the accessory subunits e, f, $g$ and A6L. $\mathrm{F}_{1}$ subunits $\gamma, \delta$ and $\varepsilon$ constitute the central stalk of complex V. Subunits b, d, $F_{6}$ and OSCP form the peripheral stalk. Protons pass from the intermembrane space to the matrix through $\mathrm{F}_{\mathrm{o}}$, which transfers the energy created by the proton electrochemical gradient to $\mathrm{F}_{1}$, where ADP is phosphorylated to ATP. One $\beta$ subunit is taken out to visualize the central stalk

oligomycin sensitivity-conferring protein (OSCP). Subunits b, $\mathrm{d}, \mathrm{F}_{6}$ and OSCP form the peripheral stalk which lies to one side of the complex. A number of additional subunits (e, f, g, and $\mathrm{A} 6 \mathrm{~L}$ ), all spanning the membrane, are associated with $\mathrm{F}_{\mathrm{o}}$ (Walker and Dickson 2006; Devenish et al. 2008). Two of the $\mathrm{F}_{\mathrm{o}}$ subunits, subunit a and subunit $\mathrm{A} 6 \mathrm{~L}$ are encoded by the mtDNA ATP6 and ATP8 genes, respectively (Anderson et al. 1981). The detailed structure of most of the bovine mitochondrial complex $\mathrm{V}$ subunits, which will not be covered in this review, has been resolved by X-ray crystallography by John Walker and his group (see, among others, (Stock et al. 1999; Gibbons et al. 2000; Cabezon et al. 2001; Arechaga et al. 2002; Cabezon et al. 2003; Dickson et al. 2006; Walker and Dickson 2006; Rees et al. 2009)).

For comparison, the subunit composition of human, yeast and E. coli ATP synthase is presented in Table 1 (Kucharczyk et al. 2009a, b, c; Watt et al. 2010).

\section{How structure relates to function: the rotary $F_{1} F_{0}$ ATP synthase}

The function of ATP synthase is to synthesize ATP from ADP and inorganic phosphate $\left(\mathrm{P}_{\mathrm{i}}\right)$ in the $\mathrm{F}_{1}$ sector. This is possible due to energy derived from a gradient of protons which cross the inner mitochondrial membrane from the intermembrane space into the matrix through the $\mathrm{F}_{\mathrm{o}}$ portion of the enzyme. The proton gradient establishes a proton-
Table 1 Subunit composition of human, yeast and E. coli ATP synthase (Kucharczyk et al. 2009a, b, c; Watt et al. 2010)

\begin{tabular}{|c|c|c|c|c|}
\hline & \multirow[t]{2}{*}{ Stoichiometry } & \multirow{2}{*}{$\begin{array}{l}\text { Bacteria } \\
\text { E. coli }\end{array}$} & \multicolumn{2}{|l|}{ Mitochondria } \\
\hline & & & S. cerevisiae & H. sapiens \\
\hline \multirow[t]{6}{*}{$\mathrm{F}_{1}$} & 3 & $\alpha$ & $\alpha$ & $\alpha$ \\
\hline & 3 & $\beta$ & $\beta$ & $\beta$ \\
\hline & 1 & $\gamma$ & $\gamma$ & $\gamma$ \\
\hline & 1 & $\varepsilon$ & $\delta$ & $\delta$ \\
\hline & 1 & - & $\varepsilon$ & $\varepsilon$ \\
\hline & 1 & $\delta$ & OSCP & OSCP \\
\hline \multirow[t]{11}{*}{$\mathrm{F}_{\mathrm{o}}$} & 1 & $\mathrm{a}$ & 6 & $\mathrm{a}$ \\
\hline & 1 & - & 8 & A6L \\
\hline & $10-15$ & $\mathrm{c}_{10-12}$ & $9_{10}$ & $\mathrm{c}_{8}$ \\
\hline & $1-2$ & $\mathrm{~b}_{2}$ & 4 & $\mathrm{~b}$ \\
\hline & 1 & - & $\mathrm{d}$ & $\mathrm{d}$ \\
\hline & 1 & - & $\mathrm{h}$ & $\mathrm{F}_{6}$ \\
\hline & 1 & - & $\mathrm{f}$ & $\mathrm{f}$ \\
\hline & t.b.d. & - & $\mathrm{e}$ & $\mathrm{e}$ \\
\hline & t.b.d. & - & $\mathrm{g}$ & g \\
\hline & 1 & - & $\mathrm{i}$ & - \\
\hline & 1 & - & $\mathrm{k}$ & - \\
\hline \multirow[t]{3}{*}{ Regulators } & 1 & - & Inh1p & $\mathrm{IF}_{1}$ \\
\hline & t.b.d. & - & Stflp & - \\
\hline & t.b.d. & - & Stf $2 p$ & - \\
\hline
\end{tabular}

t.b.d.: to be determined

motive force, which has two components: a $\mathrm{pH}$ differential and an electrical membrane potential $\left(\Delta \psi_{\mathrm{m}}\right)$ (Campanella et al. 2009). The released energy causes rotation of two rotary motors: the ring of $\mathrm{c}$ subunits in $\mathrm{F}_{\mathrm{o}}$ (Cox et al. 1984) (relative to subunit a), along with subunits $\gamma, \delta$ and $\varepsilon$ in $F_{1}$ (Boyer and Kohlbrenner 1981), to which it is attached. Protons pass $\mathrm{F}_{\mathrm{o}}$ via subunit a to the c-ring (Wittig and Schagger 2008). Rotation of subunit $\gamma$ within the $F_{1} \alpha_{3} \beta_{3}$ hexamer provides energy for ATP synthesis. This is called "rotary catalysis" (Devenish et al. 2008) and can be explained by the "binding-change" mechanism, first proposed by Boyer (Boyer 1975). This mechanism describes ATP synthesis and ATP hydrolysis at the catalytic sites, located in each of the three $\beta$ subunits, at the interface with an adjacent $\alpha$ subunit. In the case of ATP synthesis, each site switches cooperatively through conformations in which ADP and $\mathrm{P}_{\mathrm{i}}$ bind, ATP is formed, and then released. ATP hydrolysis uses the same pathway, but in reverse (Adachi et al. 2007). These transitions are caused by rotation of the $\gamma$ subunit. The $\alpha_{3} \beta_{3}$ hexamer must remain fixed relative to subunit a during catalysis, this occurs through the peripheral stalk. Complex V can therefore mechanically be divided into "rotor" (c-ring, $\gamma, \delta, \varepsilon)$ and "stator" $\left(\alpha_{3} \beta_{3}, a, b, d, F_{6}\right.$, OSCP) components (Devenish et al. 2008). 
Oligomycin is an inhibitor of proton translocation in ATP synthase, putatively binding the $\mathrm{F}_{\mathrm{o}}$ subunits $\mathrm{a}$ and $\mathrm{c}$ (Devenish et al. 2000).

$\mathrm{F}_{1} \mathrm{~F}_{\mathrm{o}}$ ATP synthases, or F-type ATPases, belong to a bigger rotor protein family, consisting of F-, V-, and A-type ATPases (Cross and Muller 2004; Lee et al. 2010). The different ATPases are categorized on the basis of their function and taxonomic origin. They are related in both structure and mechanism (Toei et al. 2010). F-type ATPases synthesize ATP, but are also capable of the reversed reaction and can hydrolyze ATP. Vacuolar or V-type ATPases use the energy derived from ATP hydrolysis to pump protons through membranes (Lee et al. 2010). V-ATPases are localized to intracellular membranes where they acidify intracellular compartments (e.g., lysosomes). They also lie in the plasma membrane, to transport protons out of highly specialized cells, like kidney cells or osteoclasts (Toei et al. 2010). Eukaryotes contain both F- and V-ATPases. In contrast, archaea typically contain only one complex which is evolutionarily closer to VATPases, called A-ATPase/synthase (Lee et al. 2010). AATPases are structurally simpler than F- or V-ATPases, but functionally more versatile, performing both ATP synthesis and ATP hydrolysis (Lee et al. 2010). F-type ATP synthases contain only one peripheral stalk, while A- and V-ATPases have two and three peripheral stalks, respectively, each made of an E-G heterodimer (Lee et al. 2010).

\section{Proteins related to mammalian ATP synthase}

\section{Coupling factors: the inhibitor protein $\mathrm{IF}_{1}$ and factor $\mathrm{B}$}

In normally respiring mitochondria, $\Delta \psi_{\mathrm{m}}$ is high (estimated at between 150 and $180 \mathrm{mV}$ negative to the cytosol), favoring ATP synthesis by $\mathrm{F}_{1} \mathrm{~F}_{\mathrm{o}}$ ATP synthase (Campanella et al. 2009). However, when mitochondrial respiration is compromised and $\Delta \psi_{\mathrm{m}}$ falls below a threshold, $\mathrm{F}_{1} \mathrm{~F}_{\mathrm{o}}$ ATP synthase can reverse, hydrolyzing ATP to pump protons through the membrane. Since depletion of ATP precipitates cell death, wasteful hydrolysis of ATP is not desirable, and must be prevented during inhibition of respiration (Devenish et al. 2008). This regulation is carried out by the inhibitor protein $\mathrm{IF}_{1}$, which inhibits mitochondrial $\mathrm{F}_{1}$-ATPase activity (Pullman and Monroy 1963) in a pH-dependent manner (Van Heeke et al. 1993). The active form predominates at $\mathrm{pH}$ values $<6.5$ (Cabezon et al. 2000). IF $_{1}$ conserves ATP at the expense of $\Delta \psi_{\mathrm{m}}$, which has been shown to be protective to cells during ischemia (Campanella et al. 2008, 2009). IF $_{1}$ acts as a homodimer, binding to two $\mathrm{F}_{1}$-ATPase sectors via subunits $\beta$ and $\gamma . \mathrm{IF}_{1}$ has no prokaryotic counterpart but is highly conserved through evolution in eukaryotic species, which indicates its functional importance (Campanella et al. 2009). Remarkably, an increased $\mathrm{IF}_{1}$ expression - as found in certain tumors and cancer cells - will inhibit both the synthetic and hydrolytic activities of complex V (SanchezCenizo et al. 2010).

Factor B, which has no prokaryotic homologue nor a counterpart in Saccharomyces cerevisiae, appears to bind to $\mathrm{F}_{\mathrm{o}}$ on the matrix side (Belogrudov and Hatefi 2002). It seems to have a regulatory function, like $\mathrm{IF}_{1}$. In addition to the classic proton-translocating pathway in $\mathrm{F}_{\mathrm{o}}$, situated at the interface of subunit a and the c-ring, it has been proposed that the membrane sector $\mathrm{F}_{\mathrm{o}}$ of animal mitochondria could harbor a second, latent proton-translocating pathway, to the assembly of which supernumerary subunits e, f, g, and A6L, as well as the ADP/ATP carrier could contribute their transmembrane segments (Belogrudov 2009). It has further been proposed that factor B occludes the latent proton-translocating pathway (Belogrudov 2009). Doing so, factor B blocks a proton leak, keeping $\Delta \psi_{\mathrm{m}}$ high and thus favoring ATP synthase activity (Belogrudov 2009).

Assembly factors: ATP11 and ATP12

ATP11 and ATP12 bind to unassembled $\beta$ and $\alpha$ subunits, respectively, by shielding their hydrophobic surfaces (Wang et al. 2000; Ackerman 2002). In the absence of these assembly factors, the $\alpha-\mathrm{F}_{1}$ and $\beta-\mathrm{F}_{1}$ aggregate within large inclusion bodies in the mitochondrial matrix (Ackerman and Tzagoloff 1990; Lefebvre-Legendre et al. 2005).

\section{TMEM70}

Transmembrane protein 70 (TMEM70) has been shown to be localized in mitochondria (Calvo et al. 2006). The Nterminal part of the cytosolic $29 \mathrm{kDa}$ precursor is cleaved to a $21 \mathrm{kDa}$ mature mitochondrial protein (Hejzlarova et al. 2011). Analysis of submitochondrial fractions has shown that TMEM70 is associated with the inner mitochondrial membrane (Hejzlarova et al. 2011). It has been demonstrated that TMEM70 is required to maintain normal expression levels and activity of complex V (Cizkova et al. 2008). It however does not interact directly with holocomplex $\mathrm{V}$ (Hejzlarova et al. 2011). A transient binding to complex V assembly intermediates has been proposed (Cameron et al. 2011). Since TMEM70 is a low abundant mitochondrial protein, like the ATP11 and ATP12 assembly factors, a regulatory role of TMEM70 in complex $\mathrm{V}$ biogenesis has been suggested (Hejzlarova et al. 2011). Further studies are necessary to clarify the exact mechanism by which TMEM70 defects lead to complex V deficiency.

Proteins associated with mammalian ATP synthase

Two ATP synthase-associated membrane proteins were identified a few years ago (Meyer et al. 2007). Both 
proteins had been identified earlier in a different context. The first one is a $6.8-\mathrm{kDa}$ mitochondrial proteolipid (MLQ protein), the second one has been denoted as diabetesassociated protein in insulin-sensitive tissue (DAPIT) (AGP protein). It has been shown recently that DAPIT has a role in maintaining ATP synthase amount in mitochondria and therefore possibly can influence cellular energy metabolism (Ohsakaya et al. 2011). The functional role of the $6.8-\mathrm{kDa}$ proteolipid as ATP synthase-associated protein still has to be elucidated (Meyer et al. 2007).

\section{Complex V assembly}

Current knowledge about the assembly of ATP synthase is mainly based on research performed on assembly-deficient yeast mutants (Kucharczyk et al. 2009a, b, c). Nevertheless complex $\mathrm{V}$ assembly remains puzzling and partially hypothetical because the biogenesis of ATP synthase is not easily studied biochemically (Rak et al. 2009). This is due to rapid turnover of subunits of $F_{o}$ and the stator in these yeast mutants (Rak et al. 2009). This problem has been addressed lately by labeling and tracking the mitochondrial gene products of $F_{o}$ in isolated mitochondria (Rak et al. 2011).

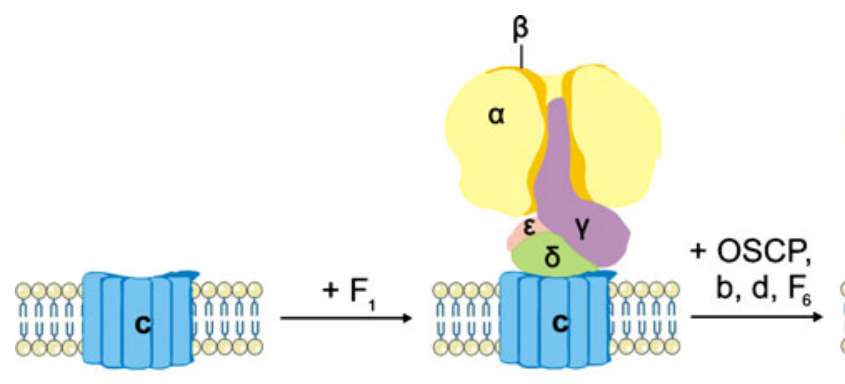

Fig. 2 Complex V assembly and dimerization. The current working model is based on assembly of the c-ring followed by binding of $F_{1}$, the stator arm, and finally of subunits a and A6L. Two ATP synthase
It is known that the assembly of $\mathrm{F}_{1}$, the stator and the cring occurs separately, but the assembly sequence of subunits into the different modules and the sequence between the modules is not entirely clear (Velours and Arselin 2000; Wittig et al. 2010). Using clear native polyacrylamide gel electrophoresis (CN-PAGE), performed with milder detergents than blue native PAGE (BN-PAGE), it has been shown in human mitochondria lacking mtDNA (and therefore subunits a and A6L) that ATP synthase can assemble into a complex with a mass of $550 \mathrm{kDa}$ (Wittig et al. 2010). This is a little bit smaller than holocomplex V $(597 \mathrm{kDa})$, suggesting that the only subunits lacking in the $550 \mathrm{kDa}$ complex are subunit a $(24.8 \mathrm{kDa})$ and $\mathrm{A} 6 \mathrm{~L}(8 \mathrm{kDa})$, and possibly the small associated proteins AGP and MLQ (Wittig et al. 2010). This implies that the so-called $\mathrm{F}_{1}-\mathrm{z}$ complex (or $\mathrm{V}^{*}$ (Nijtmans et al. 1995)) contains the c-ring and that it is a breakdown product of the $550 \mathrm{kDa}$ complex under the harsher conditions of BN-PAGE instead of an assembly intermediate (Wittig et al. 2010). Based on these findings and on previous yeast work (reviewed in (Kucharczyk et al. 2009a, b, c; Rak et al. 2009)) a proposal regarding the assembly of mammalian ATP synthase has been made: assembly of the c-ring followed by binding of $F_{1}$, the stator arm, and finally of subunits a and A6L (Wittig et al. 2010) (Fig. 2). A recent yeast study indicated that ATP synthase is
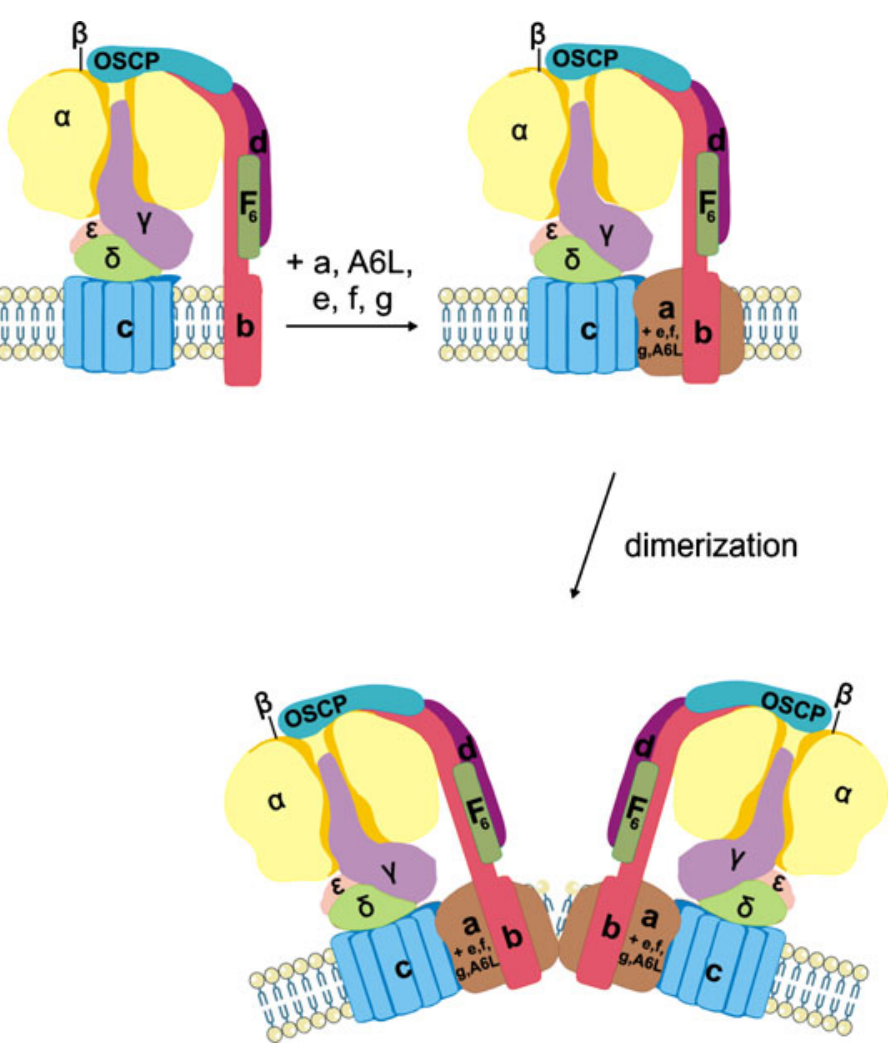

monomers dimerize via the $\mathrm{F}_{\mathrm{o}}$ sector, where subunits $\mathrm{a}, \mathrm{e}, \mathrm{g}, \mathrm{b}$ and A6L stabilize the monomer-monomer interface 
formed from three different modules: the c-ring, $F_{1}$ and the Atp6p/Atp8p complex (Rak et al. 2011). It is proposed that ATP synthase assembly in yeast involves two separate pathways $\left(\mathrm{F}_{1} / \mathrm{Atp} 9 \mathrm{p}\right.$ and Atp6p/Atp8p/2 stator subunits/ Atp10p chaperone) that converge at the end stage (Rak et al. 2011). The final addition of the mitochondrial encoded subunits to mammalian complex $\mathrm{V}$ is in line with the yeast studies describing that the expression of yeast subunits 6 and 8 is translationally regulated by the $F_{1}$ sector (Rak and Tzagoloff 2009; Rak et al. 2011). Therefore a balanced output can be achieved between the nuclear encoded and mtDNA encoded subunits. The role of complex V subunits in the assembly process has been studied. The peripheral stalk is important for the stability of the c-ring $/ \mathrm{F}_{1}$ complex (Rak et al. 2009). It has been described that subunit A6L provides a physical link between the proton channel and the other subunits of the peripheral stalk (Stephens et al. 2003). $F_{1}$ subunit $\varepsilon$ is indispensable for the assembly of holocomplex V (Havlickova et al. 2010). More specifically, subunit $\varepsilon$ plays a role in the biosynthesis and assembly of the $F_{1}$ sector and seems to be involved in the incorporation of subunit $\mathrm{c}$ to the rotor structure of ATP synthase (Mayr et al. 2010). Subunit c isoforms (P1, P2, and P3) are not functionally interchangeable since their targeting peptides have different roles, varying from mitochondrial import to the regulation of the assembly and function of other OXPHOS complexes (Vives-Bauza et al. 2010). On the contrary, an example of over engineering is the $F_{1}$ subunit $\gamma$, which only needs its $\mathrm{N}$ terminal helix together with subunit $\delta$ in an upward position to catalyze ATP synthesis (Iino et al. 2009; Mnatsakanyan et al. 2009).

\section{Complex V di- and oligomerization}

An important role of subunits a and $\mathrm{A} 6 \mathrm{~L}$ is the stabilization of holocomplex V (Wittig et al. 2010). It has been shown that ATP synthase is organized in dimers and higher oligomers (Arnold et al. 1998; Schagger and Pfeiffer 2000; Arselin et al. 2003; Krause et al. 2005; Wittig and Schagger 2005; Thomas et al. 2008; Wittig and Schagger 2008). The interaction between two ATP synthase monomers mainly takes place via the $F_{o}$ sector (Fig. 2). It has been suggested that subunit a forms the most important basis for dimerization since it has a high number of predicted transmembrane helices (Wittig and Schagger 2008). Next to subunit a, subunits of the stator stalk and accessory subunits (e, g, b, and A6L) stabilize the monomer-monomer interface (Bisetto et al. 2008; Wittig and Schagger 2008; Wittig et al. 2010). Another protein that has a role in the stabilization of di- and oligomers is $\mathrm{IF}_{1}$. Mature $\mathrm{IF}_{1}$ is only bound to di- and oligomeric ATP synthase in mammals (Wittig et al. 2010). IF $_{1}$ links two ATP synthases via the $F_{1}$ sector (Devenish et al. 2008).
Monocomplex V is fully capable of ATP synthesis. Nevertheless forming di- and oligomers has been proven to be beneficial to the cell. First, di- and oligomers provide stabilization of complex $\mathrm{V}$, which is continuously subject to dynamic rotor/ stator interactions and can therefore be dissociated more easily (Wittig and Schagger 2009). Secondly, oligomerization of complex $\mathrm{V}$ facilitates ATP synthesis (Strauss et al. 2008). This happens because dimer ribbons of ATP synthase shape the inner mitochondrial membrane (Strauss et al. 2008). Because of the angular association of two monomers, dimerization leads to bending of the inner mitochondrial membrane, creating protrusions of the membrane in the matrix, called mitochondrial cristae. Clustering of ATP synthase dimers at the apex of the cristae creates a strong local positive curvature which generates a proton trap. This facilitates ATP synthesis (Strauss et al. 2008). IF 1 contributes to this mechanism and is therefore beneficial during ischemia, since ATP synthesis can be preserved when mitochondrial respiration is compromised (Campanella et al. 2008, 2009).

\section{Complex V and mitochondrial morphology}

The association of ATP synthase dimers as generating the tubular cristae has been hypothesized by Allen (Allen 1995). The link between dimerization of mitochondrial ATP synthase, through subunits $e, g$, and -as described just recently, subunits $i, k$, and the biogenesis of cristae has been provided by studying yeast cells (Paumard et al. 2002; Thomas et al. 2008; Wagner et al. 2010). Due to cristae formation, the inner mitochondrial membrane can be divided into the inner boundary membrane and the cristae membrane. The cristae are connected to the inner boundary membrane by narrow structures, called crista junctions. In yeast, it has been suggested that the formation of cristae and crista junctions in mitochondria depends on antagonism between Fcj1 (formation of crista junction 1) and subunits e/g (Rabl et al. 2009). $\mathrm{IF}_{1}$ contributes to cristae formation (Campanella et al. 2008). Other components such as prohibitins or OPA1 or others yet to be identified also could contribute to crista junction and cristae tip formation (Rabl et al. 2009; Zick et al. 2009).

It has been shown in yeast that in the absence of complex $\mathrm{V}$ dimerization (by depleting subunits $e$ and $g$ ) normal cristae formation is hampered, resulting in onionlike structures (Paumard et al. 2002). Inhibition of $F_{1}$ synthesis in yeast leads to an absence of cristae (Paumard et al. 2002; Lefebvre-Legendre et al. 2005). Another yeast study describes that the lack of Atp6p rather than an ATP production deficit modifies the overall structure of the mitochondria (Kucharczyk et al. 2009a, b, c). Taken together, the complex V structure and not its enzymatic 
activity seems to modify cristae morphology, which is in agreement with the necessity of ATP synthase dimerization for mitochondrial cristae formation (Paumard et al. 2002; Campanella et al. 2008; Strauss et al. 2008).

\section{Complex V deficiency}

Complex V deficiency is one of the rarer OXPHOS deficiencies. Based on the results of mitochondrial biochemical diagnostics in Nijmegen in the years 2005-2009, complex I, IV and combined enzyme deficiencies are encountered most frequently $(8 \%, 5 \%$ and $7 \%$, respectively of 1,406 fresh muscle samples examined), followed by complex III (3\%), complex II (2\%) and complex V (1\%) (Rodenburg 2011).

\section{Biochemical diagnosis}

Measurement of the mitochondrial energy-generating system (MEGS) capacity in fresh muscle tissue is a powerful tool to assess mitochondrial function and to detect deficiencies of complex $\mathrm{V}$ and other OXPHOS complexes. The MEGS capacity can be examined in detail by measurement of ${ }^{14} \mathrm{CO} 2$ production rates from oxidation of ${ }^{[1-14 C]}$ pyruvate and carboxyl-14C-labeled TCA cycle intermediates in combination with measurement of ATP production in intact mitochondria from a muscle biopsy (Janssen et al. 2006), or by examining mitochondrial respiration by measuring oxygen consumption in digitonin-permeabilized cells (Jonckheere et al. 2010). A reduced pyruvate oxidation rate that is normalized by addition of an uncoupler, e.g. carbonyl cyanide 3chlorophenyl hydrazone (CCCP), indicates a defect in complex V, the adenine nucleotide transporter, or the phosphate carrier (Rodenburg 2011). Enzyme analysis of complex V (mtATPase) in skeletal muscle biopsy and in cultured fibroblasts remains the mainstay of the diagnostic process (Janssen et al. 2003). In Nijmegen, mtATPase activity is measured spectrophotometrically in isolated mitochondria from fresh muscle tissue and fibroblasts as described (Rodenburg 2011): a solution of $980 \mu$ l containing $250 \mathrm{mM}$ sucrose, $50 \mathrm{mM} \mathrm{KCl}, 30 \mathrm{mM}$ phosphate buffer $\mathrm{pH}$ 7.4, $25 \mathrm{mM}$ phosphate buffer $\mathrm{pH} 8.0,0.1 \mathrm{mM}$ phosphoenolpyruvate, $5 \mathrm{mg} / \mathrm{L}$ Ap5A, $0.3 \%$ BSA, $0.2 \mathrm{mM}$ EGTA, $3 \mathrm{mM}$ ATP, $7.5 \mathrm{mM} \mathrm{MgCl} 2,250 \mu \mathrm{M}$ NADH, $2.5 \mathrm{U} /$ $\mathrm{ml}$ lactate dehydrogenase, and $1.5 \mathrm{U} / \mathrm{ml}$ pyruvate kinase is incubated for $10 \mathrm{~min}$ at $37^{\circ} \mathrm{C}$. A mitochondrial suspension is freeze-thawed three times and $20 \mu \mathrm{l}$ is added to the reaction mixture, mixed and transferred to a cuvette, after which the absorption at $340 \mathrm{~nm}$ is measured for $8 \mathrm{~min}$. Simultaneously, the absorption is measured in a second cuvette after addition of $1 \mu \mathrm{l}$ of an $8 \mathrm{mg} / \mathrm{ml}$ oligomycin solution in ethanol to the mitochondrial suspension and the reaction mixture. The oligomycin-sensitive activity of complex $\mathrm{V}$ is calculated using an $\varepsilon_{340}$ for NADH of $6.22 \times 10^{3} \mathrm{~L} / \mathrm{mol}$.cm and is expressed in units (the amount of enzyme required to convert $1 \mu \mathrm{mol}$ NADH per min) per unit cytochrome oxidase (COX) (Cooperstein and Lazarow 1951) activity. Analysis of complex V in frozen tissue is considered to be less reliable than in fresh muscle tissue ((Kirby et al. 2007), and personal experience (data not shown)). In addition, BN-PAGE followed by western blotting (Schagger and von Jagow 1991; Nijtmans et al. 2002) and in-gel activity measurements of ATP hydrolysis (Nijtmans et al. 2002) can be performed to assess the amount and activity of complex V. BN-PAGE can also provide information about the assembly of complex $\mathrm{V}$ (Cizkova et al. 2008; Jonckheere et al. 2008).

Molecular genetics

Hitherto, complex $\mathrm{V}$ mutations have been described in the mtDNA encoded ATP6 (MT-ATP6) and ATP8 (MT-ATP8) genes. ATP synthase deficiency due to the nuclear encoded ATP12 and TMEM70 genes has also been described (De Meirleir et al. 2004; Cizkova et al. 2008). Interestingly, only one mutation has hitherto been described in a nuclear encoded structural complex V subunit, ATP5E (Mayr et al. 2010).

ATP synthase subunit a; MT-ATP6 (MIM ID +516060)

Mutations in MT-ATP6 were the first complex V genetic defects to be reported (Holt et al. 1990) and have been described most frequently to date. The classical clinical picture is found in $\mathrm{m} .8993 \mathrm{~T}>\mathrm{G} / \mathrm{C}$ and $\mathrm{m} .9176 \mathrm{~T}>\mathrm{G} / \mathrm{C}$ mutations and covers a spectrum which varies between isolated ataxia, NARP, bilateral striatal necrosis, to Leigh or Leigh-like syndromes (www.mitomap.org). Also other clinical features have been associated with MT-ATP6 mutations (www.mitomap.org). Below, an overview of a part of the hitherto described mutations in this gene is given, i.e., the mutations that have been well studied in humans and in yeast and those that, in our opinion, add interesting information regarding the clinical expression of mitochondrial complex $\mathrm{V}$ diseases. They have been outlined in relation to their clinical picture.

m.8993T $>G$ This mutation leads to NARP (typically $<90$ $95 \%$ heteroplasmy) or MILS (when $>95 \%$ heteroplasmy). Biochemically a decreased ATPase activity (measured spectrophotometrically) and a severely decreased ATP production rate (until $70 \%$ when $>90 \%$ heteroplasmy) is observed (Tatuch and Robinson 1993; Trounce et al. 1994; Baracca et al. 2000; Garcia et al. 2000; Pallotti et al. 2004; 
Morava et al. 2006; Sgarbi et al. 2006). Subunit a has two functions: (i) it conducts protons from the inner mitochondrial membrane to the matrix, which (ii) leads to the rotation of the ring of c-subunits that contacts subunit a in the membrane. The resulting mechanical energy is used to induce conformational changes at the level of the catalytic sites in the $\mathrm{F}_{1}$ extra-membrane domain that favor ATP synthesis (Sgarbi et al. 2006; Kucharczyk et al. 2010). The m.8993T $>$ G point mutation leads to p.Leu156Arg. Leu156 is highly conserved in eukaryotes (Boyer 1997; Sgarbi et al. 2006) and is situated in the region of subunit a that regulates proton translocation coupled to rotation of the cring (Sgarbi et al. 2006; Kucharczyk et al. 2009a, b, c). The introduction of a positively charged amino acid (arginine) instead of the hydrophobic leucine causes a structural change that has been shown to affect rotation of the c-ring (Sgarbi et al. 2006). The proton flux through $F_{o}$ is slower, but not blocked (Sgarbi et al. 2006). Furthermore, it has been shown that ATP synthase still assembles and oligomerizes correctly. This is confirmed by an intact oligomycin sensitivity (Cortes-Hernandez et al. 2007), a property that is lost when enzyme structure is severely altered (MatsunoYagi et al. 1985; Penefsky 1985). The assembly of $F_{1}$ with $\mathrm{F}_{\mathrm{o}}$ has only been shown to be delayed because of a slower subunit a synthesis or an increased subunit a instability and degradation (D'Aurelio et al. 2010). Taken together, the severe impairment of ATP synthesis is due to functional inhibition in a correctly assembled ATP synthase (CortesHernandez et al. 2007).

$m .8993 T>C$ The clinical picture is similar to the m.8993T> G mutation, but is generally milder (de Vries et al. 1993; Vazquez-Memije et al. 1998; Morava et al. 2006; Debray et al. 2007). The mutation results in p.Leu156Pro. Opposite to the positive charged arginine in the m.8993 $>$ G mutation, proline is a non-charged amino acid. Biochemically, ATP synthesis is not severely affected (Sgarbi et al. 2006). So this does not fully explain the NARP or MILS phenotypes seen in patients. It has been shown that the m.8993T $>$ C mutation favors reactive oxygen species (ROS) production, which is believed to be the major pathogenic mechanism (Sgarbi et al. 2006). ROS plays a major role in the pathogenesis of neurological diseases related to mitochondrial dysfunction (Lenaz et al. 2004; Wallace 2005).

$m .9176 T>G / C$ The clinical picture is characterized by familial bilateral striatal necrosis (FBSN) and Leigh syndrome (Thyagarajan et al. 1995; Dionisi-Vici et al. 1998). A hereditary spastic paraplegia-like disorder has been described in a family carrying the homoplasmic m.9176T $>$ C mutation (Verny et al. 2011). The mutations also change a highly conserved hydrophobic leucine residue into arginine $(\mathrm{m} .9176 \mathrm{~T}>\mathrm{G})$ or proline $(\mathrm{m} .9176 \mathrm{~T}>\mathrm{C})$ at position 217 of the protein. Position 217 of subunit a also lies in proximity to the c-ring (Kucharczyk et al. 2009a, b, c). It has been shown in human cells with a high degree of heteroplasmy that the m.9176T $>\mathrm{G}$ mutation severely decreases the rate of ATP production (Carrozzo et al. 2001). In yeast carrying the m.9176T $>\mathrm{G}$ mutation, it has been described that that incorporation of subunit a into ATP synthase was almost completely prevented (Kucharczyk et al. 2009a, b, c). This resulted in a disturbed assembly which profoundly altered mitochondrial morphology (Kucharczyk et al. 2009a, b, c). This finding is in contrast to the m.8993T $>$ G mutation, where the assembly is not altered (as mentioned before). Taken together, the pathogenicity of m.9176T $>$ G may not be limited to a bio-energetic deficiency, but may also be attributed to an altered mitochondrial and cristae morphology (Kucharczyk et al. 2009a, b, c). Also the m.9176T $>$ C mutation has been studied in yeast, only showing a mild decrease in ATP production (Kucharczyk et al. 2010). There is a poor correlation between genotype and phenotype for the m.9176T>C mutation (Kucharczyk et al. 2010). Additional determinants may be responsible and are a plausible explanation for this finding. One of these determinants has been proposed to be the higher degree of oligomycin vulnerability in the mutant than in wild type (Kucharczyk et al. 2010).

In tightly coupled mitochondria the oxygen consumption rate and ATP synthesis depend on each other (Rak et al. $2007 a, b)$. Therefore it is not very surprising to see a decreased respiratory activity in many ATP synthase defective mutants (Rak et al. 2007a, b). In several yeast models with NARP-MILS mutations (atp6-p.Leu183Pro (Kucharczyk et al. 2009a, b, c), atp6-p.Leu183Arg (Rak et al. 2007a, b), atp6-p.Leu247Arg (Kucharczyk et al. 2009a, b, c), atp6-p.Leu247Pro (Kucharczyk et al. 2010), and $\Delta$ atp6 (Rak et al. 2007a, b)), it has been shown that there is a linear correlation between ATP synthase activity and complex IV activity (Kucharczyk et al. 2010). So it appears that complex IV is an important target for the co-regulation of electron transfer and ATP synthesis in mitochondria (Kucharczyk et al. 2010).

$m .9035 T>C, m .9185 T>C, m .9191 T>C, m .8851 T>C$ These mutations are illustrations of variants of the earlier described NARP-MILS clinical spectrum. m.9035T $>C$ has been found in a family with maternally transmitted cognitive developmental delay, learning disability, and progressive ataxia (Sikorska et al. 2009). Mutant cybrids had less than half of the steady-state content of ATP and a substantial higher basal level of reactive oxygen species (ROS) (Sikorska et al. 2009). m.9185T >C (p.Leu220Pro) results in a phenotype varying from mild learning difficulties and foot deformities, ataxia, an acute neurological presentation with complete recovery, to Leigh syndrome 
(Moslemi et al. 2005; Childs et al. 2007). m.9191T $>C$ (p. Leu222Pro) has been described in a patient with Leigh syndrome (Moslemi et al. 2005). The pathogenic mechanism of the m.9185T $>\mathrm{C}$ and $\mathrm{m} .9191 \mathrm{~T}>\mathrm{C}$ mutations is unknown, but they are situated in a highly conserved region of the protein. The observed phenotypical differences are proposed to result from additional genetic and/or environmental modifying factors (Childs et al. 2007). A patient suffering from bilateral striatal necrosis and harboring a m.8851T $>\mathrm{C}$ mutation has also been described (De Meirleir et al. 1995). This phenotype is less severe than found in typical Leigh disease (De Meirleir et al. 1995).

$\triangle T A 9205$ This mutation has been reported in a patient with seizures and lactic acidemia (Seneca et al. 1996). $\triangle$ TA9205 is situated at the junction between the two genes MT-ATP6 and $M T C O 3$ (which codes for COX3, a complex IV subunit). It removes the termination codon from RNA14, the bi-cistronic RNA unit encoding MT-ATP8 and MT$A T P 6$, which has been shown to cause a decrease in the steady-state level of the mutated RNA14 (Temperley et al. 2003). The level of $R N A 15$, the RNA transcribed from MTCO3, is not affected (Temperley et al. 2003). This mutation illustrates how a mtDNA mutation can influence the turnover of a human mitochondrial mRNA.

Modifiers Phenotypical variations between patients harboring the same mtDNA mutation have classically been attributed to mtDNA heteroplasmy. However, a discrepancy between the levels of mutant mtDNA and disease severity is sometimes observed (D'Aurelio et al. 2010). The mtDNA background has been shown to play an important role in modulating the biochemical defects and clinical outcome (D'Aurelio et al. 2010). MT-ATP6 mutations m.8741T $>\mathrm{G}$ and $\mathrm{m} .8795 \mathrm{~A}>\mathrm{G}$ have been shown to be protective factors for the m.8993T $>$ G MILS mutation (Mkaouar-Rebai et al. 2009). A MT-ATP6 polymorphism, m.9055G $>$ A, significantly reduces the risk of Parkinson disease, especially in women (van der Walt et al. 2003). The mitochondrial haplogroup $\mathrm{J}$ has been shown to be associated with longevity and protection against certain diseases (Verny et al. 2011). Vice versa, respiratory chain defects upstream of ATP synthase contribute to ATP synthesis impairment, worsening the biochemical and clinical phenotype, e.g., of m.8993T $>\mathrm{G} / \mathrm{C}$ and m.9176T $>\mathrm{G}$ mutations (D'Aurelio et al. 2010). The germ-line mutation $\mathrm{m} .8932 \mathrm{C}>\mathrm{T}$ has, together with somatic mtDNA mutations in the cytochrome oxidase subunit I (COI) gene, been associated with prostate cancer (Petros et al. 2005; Arnold et al. 2009). The mtDNA variants $\mathrm{m} .8836 \mathrm{~T}>\mathrm{G}, \mathrm{m} .9016 \mathrm{~A}>\mathrm{G}, \mathrm{m} .9101 \mathrm{~T}>\mathrm{C}$, m.9139G $>$ A have been linked with patients who had Leber hereditary optic neuropathy (LHON) or LHON-like optic neuropathies (Lamminen et al. 1995; Povalko et al. 2005;
Abu-Amero and Bosley 2006; La Morgia et al. 2008). Hence, mtDNA background can explain the biochemical and clinical variations observed between patients with the same mutation and a comparable mutation load. This also illustrates the role of mtDNA variants in the complexity of mtDNA disease expression. In general, phenotypic variability is proposed to be the result of interactions between the casual genes, genetic background or modifier genes (mitochondrial or nuclear), and probably environmental factors (Carelli et al. 2002).

ATP synthase subunit A6L; MT-ATP8 (MIM ID +516070)

$m .8529 G>A$ This homoplasmic mutation has been found in a 16-year-old patient presenting with apical hypertrophic cardiomyopathy and neuropathy (Jonckheere et al. 2008). The mutation is situated in an overlap region between MTATP8 and MT-ATP6, resulting in a silent change in MTATP6 (Met1Met; ATG $>$ ATA), but introducing a premature stopcodon in a conserved region of MT-ATP8 (p.Trp55X) (Jonckheere et al. 2008). This resulted in an improper assembly and a decreased activity of the complex $\mathrm{V}$ holoenzyme (Jonckheere et al. 2008).

$m .8528 T>C$ This homoplasmic mutation has been found in four unrelated patients who presented as infants with isolated hypertrophic cardiomyopathy and congestive heart failure, evolving to multisystem disease (Ware et al. 2009). Electron microscopy of muscle tissue showed increased variation in size and shape of mitochondria with dense parallel cristae in one patient (Ware et al. 2009). For A6L, m.8528T $>\mathrm{C}$ (p. Trp55Arg) is a pathogenic missense mutation, replacing a hydrophobic tryptophan into a basic arginine in a conserved region of the subunit. In subunit a, the nucleotide alteration results in the change of the initiation methionine to threonine, but the effect of this mutation on the function of this subunit is not clear (Ware et al. 2009).

Taken together, the MT-ATP 8 mutations $\mathrm{m} .8529 \mathrm{G}>\mathrm{A}$ and m.8528T $>C$ both affect the same amino acid (tryptophan) and clinically cause a cardiomyopathy.

m. $8411 A>G$ The de novo mutation with $97 \%$ heteroplasmy has been described in a patient with psychomotor delay, epilepsy, tetraplegia, congenital deafness, central blindness and swallowing difficulties (Mkaouar-Rebai et al. 2010). $\mathrm{He}$ died at the age of 10 years. Brain MRI showed involvement of the interpeduncular nucleus, the central tegmental tract, the white matter and the cerebellum. This leucodystrophy phenotype differs from the other mutations described in MT-ATP8, where cardiac involvement predominates. Leucodystrophy has been described in two siblings with Leigh syndrome harboring the $\mathrm{m} .9176 \mathrm{~T}>\mathrm{C}$ mutation 
in MT-ATP6 (Hung and Wang 2007). It should be noted that complex $\mathrm{V}$ enzyme analysis was not performed in this patient (Mkaouar-Rebai et al. 2010), and therefore the pathogenicity of the m.8411 $\mathrm{A}>\mathrm{G}$ mutation has not been firmly established yet.

\section{ATP12 (MIM ID *608918)}

A homozygous $\mathrm{T}>\mathrm{A}$ mutation, changing an evolutionary conserved tryptophan to an arginine at position 94 (p.Trp94Arg) of the nuclear encoded complex V assembly gene ATP12 has been found in a patient who presented with a severe neonatal encephalopathy and dysmorphic features, evolving to basal ganglia atrophy within months and death at the age of 14 months (De Meirleir et al. 2004; Meulemans et al. 2010). The mutation resulted in a severely decreased complex $\mathrm{V}$ amount and activity. It was hypothesized that the change of a neutral polar amino acid (tryptophan) into a basic one (arginine) resulted in an ATP12 protein that was no longer able to mediate $F_{1}$ assembly (De Meirleir et al. 2004). Later, it has been shown in a yeast model that the p.Trp94Arg mutation decreases the solubility of the protein, implying that the primary impact of the mutation was a change in physical rather than functional parameters (Meulemans et al. 2010). Mitochondrial morphology has been studied in fibroblasts, but no alterations compared to control cells could be observed (Meulemans et al. 2010).

\section{TMEM70 (MIM ID *612418)}

The TMEM70 gene encodes a mitochondrial protein, transmembrane protein 70 . A common splice site mutation and an isolated frameshift mutation have been described in the TMEM70 gene particularly in a homogeneous ethnic group (Romanies), with a clinical phenotype characterized by neonatal mitochondrial encephalocardiomyopathy, lactic acidosis and dysmorphic features (Cizkova et al. 2008). The description of four novel mutations in the TMEM70 gene has confirmed and expanded this classical clinical picture with early onset cataract, gastrointestinal dysfunction, congenital hypertonia and a fetal presentation of the syndrome (Spiegel et al. 2011). One patient with a milder clinical phenotype carrying the common splice site mutation and a missense variant has also been described (Shchelochkov et al. 2010). This phenotype corroborates with two reported patients who are compound heterozygous for the common splice site mutation and a frame-shift mutation in exon 1 (Honzik et al. 2010; Cameron et al. 2011). It was shown that TMEM70 is required to maintain normal expression levels of complex $\mathrm{V}$ (Cizkova et al. 2008). The exact mechanism behind this remains to be elucidated, although it has been suggested that TMEM70 is involved in complex V biogenesis (Cizkova et al. 2008).
ATP synthase subunit epsilon; ATP5E (MIM ID *606153)

Recently, a homozygous missense mutation c.35A $>\mathrm{G}$ (p.Tyr12Cys) has been described in exon 2 of the ATP5E gene (Mayr et al. 2010). The patient was a 22 year old woman presenting with neonatal onset, lactic acidosis, 3methylglutaconic aciduria, and mild mental retardation. She developed peripheral neuropathy (Mayr et al. 2010). The mutation caused a decrease in the amount and activity of holocomplex V. Remarkably, subunit $\mathrm{c}$ was found to accumulate, in contrast to the other investigated complex $\mathrm{V}$ subunits, and in contrast to what was found in patients with a mutation in the TMEM70 (Honzik et al. 2010) and ATP12 (De Meirleir et al. 2004) genes (Mayr et al. 2010). Using pulse-chase experiments, this study pointed to the crucial role of subunit $\varepsilon$ in the biosynthesis and assembly of the $F_{1}$ part of ATP synthase. Moreover, subunit $\varepsilon$ seems to be involved in the incorporation of subunit $\mathrm{c}$ into the rotor (Mayr et al. 2010).

\section{Therapy}

Current available treatment options for patients with mitochondrial diseases are mainly supportive. Therefore, a lot of effort is put into the search for both pharmacological and genetic approaches to cure this devastating group of disorders (for reviews, see (DiMauro et al. 2006; Koene and Smeitink 2009, 2010)). Focusing here on complex V deficiency, current research has mainly covered the therapy of mtDNA mutations.

\section{Antioxidants}

As mentioned above, complex $\mathrm{V}$ mutations can increase ROS production which is deleterious for the cell. The antioxidants $\mathrm{N}$-acetylcysteine (NAC) and dihydrolipoic acid (DHLPA) have therefore been tested in fibroblasts harboring $97 \% \mathrm{~m} .8993 \mathrm{~T}>\mathrm{G}$ mutant mtDNA. It has been shown that they significantly improved mitochondrial respiration and ATP synthesis in these cells (Mattiazzi et al. 2004).

\section{Substrates: $\alpha$-Ketoglutarate/Aspartate}

In yeast studies, it has been suggested that forcing substrate-level phosphorylation to work overtime may counteract the energy crisis due to OXPHOS impairment (Schwimmer et al. 2005).

For the application of this approach in OXPHOSdeficient human cells, exogenous substrates capable of stimulating the Krebs cycle flux while at the same time removing the excess of reduced nicotinamide adenine 
dinucleotide (NADH) have been chosen (Sgarbi et al. 2009). It has been demonstrated that homoplasmic cybrids harboring the $\mathrm{m} .8893 \mathrm{~T}>\mathrm{G}$ mutation were protected from cell death and had an ATP content similar to controls after supplementation of the culture medium with $\alpha$ ketoglutarate and aspartate (Sgarbi et al. 2009).

\section{Affecting heteroplasmy of the mtDNA (gene-shifting)}

This genetic approach aims to force a shift in heteroplasmy, reducing the ratio of mutant to wild-type genomes (also called gene-shifting) (DiMauro et al. 2006). Various methods can be applied to achieve this goal.

Allotopic expression Here, a normal version of a mutant mtDNA-encoded protein is imported into the nucleus. For example, MT-ATP6 can be converted from the mitochondrial into the nuclear genetic code (Manfredi et al. 2002; DiMauro et al. 2006). To be transported to the mitochondrion, it has to be provided with a mitochondrial targeting signal, of which the genetic sequence can be borrowed from another mtDNA-encoded protein. The biochemical defect in cybrid cell lines harboring the m.8993T $>$ G mutation has been corrected successfully using this strategy (Manfredi et al. 2002).

Xenotopic expression The correction here implies the transfection of mammalian cells with either mitochondrial or nuclear genes from other organisms encoding the protein of interest (DiMauro et al. 2006). This has also been applied to human cybrids harboring the m.8993T $>\mathrm{G}$ mutation by expressing the nDNA encoded ATPase6 protein of the alga Clamydomonas reinhardtii, which already possessed the mitochondrial targeting sequence since it is nuclear encoded (Ojaimi et al. 2002). Also this approach could correct the biochemical defect in these cells (Ojaimi et al. 2002).

Restriction endonucleases These are specific proteins that cut mutant mtDNA but not wild type mtDNA (DiMauro et al. 2006). For example, the m.8993T $>\mathrm{G}$ mutation creates a unique cleavage site for the restriction endonuclease SmaI. The gene for $S m a I$ was fused to a mitochondrial targeting sequence and expressed in heteroplasmic mutant cybrid cells, which lost mutant mtDNA and recovered biochemically (Tanaka et al. 2002; Alexeyev et al. 2008).

Oligomycin It has been shown that culturing heteroplasmic m.8993 $>$ G cybrid cells in medium containing oligomycin (complex V inhibitor) and galactose (which forces the cells to rely on oxidative metabolism for ATP production) allowed for the selection of wild type over mutant mtDNA (Manfredi et al. 1999).
Germline therapy

It has been proposed that nuclear transfer techniques may be an approach for the prevention of transmission of human mtDNA disease (Sato et al. 2005; Brown et al. 2006). Briefly, this means that the pronucleus of an oocyte, or zygote, of a woman carrying mutated mtDNA could be transferred to a donor enucleated oocyte, or zygote, carrying wild type mtDNA (DiMauro et al. 2006; Craven et al. 2010). In that way, the offspring will carry all the nuclear - and physiognomonic - traits of the parents, but not the mutated mtDNA of the mother (DiMauro et al. 2006). Two successful approaches have recently been described.

Metaphase II spindle transfer between unfertilized metaphase II oocytes It has been demonstrated in mature nonhuman primate oocytes (Macaca mulatta) that the mitochondrial genome can be efficiently replaced by spindlechromosomal complex transfer from one egg to an enucleated, mitochondrial-replete egg (Tachibana et al. 2009). Subsequently, it was possible to have normal fertilization and embryo development. The offspring was healthy (Tachibana et al. 2009).

Pronuclear transfer between zygotes This is essentially the same procedure, except that the nuclear material, both the male and female pronucleus, is removed after fertilization (Tachibana et al. 2009). It has been shown that transfer of pronuclei between abnormally fertilized human zygotes resulted in minimal carry-over of donor zygote mtDNA and is compatible with onward development of the blastocyst stage in vitro (Craven et al. 2010).

There have been few randomized controlled trials for the treatment of mitochondrial disease (Chinnery et al. 2006). To date, there is no clear evidence supporting the use of pharmacological agents, non-pharmacological treatments (vitamins and food supplements), and physical training in patients with mitochondrial disorders (Chinnery et al. 2006). Although very promising, all genetic techniques are still in an experimental phase and different technical, ethical and safety issues still have to be solved (DiMauro et al. 2006; Kucharczyk et al. 2009a, b, c; Tachibana et al. 2009; Craven et al. 2010). Nevertheless, they do allow cautious optimism for the future.

Prenatal and preimplantation diagnosis

Since current therapeutic options for mitochondrial diseases are insufficient, the possibility of prenatal diagnosis for fetuses at risk is a valuable alternative. If it concerns a known nuclear genetic defect, the mutation can directly be searched for in fetal tissue. If the complex V deficiency is 
caused by a mtDNA defect (in MT-ATP6 or MT-ATP8), prenatal diagnosis is complicated by several factors. First, the correlation between mutant mtDNA load and disease severity is poor in many mtDNA diseases. Second, the heteroplasmy level differs between tissues and in one tissue through time (Poulton and Marchington 2002). In this context, the m.8993 mutation (NARP mutation) is an exception. There is a correlation between mutant mtDNA load and disease severity (Poulton and Marchington 2002). Moreover, it has been shown that the placental/ amniotic mutant loads do reflect the NARP mutant mtDNA load in the whole fetus (Dahl et al. 2000; Steffann et al. 2007). Finally, it is suggested that the heteroplasmy level remains stable after 10 weeks of gestation (Steffann et al. 2007). A mutation load $<30 \%$ gave rise to healthy children at 2 7 years of age, while the correlation between an intermediate mutant load $(>30 \%$ and $<80 \%)$ and disease severity still needs to be assessed (Steffann et al. 2007). Hitherto termination of pregnancy has been preferred in case of intermediate mutant loads (Steffann et al. 2007). Remarkably, the intermediate mutant loads question the observation that the m.8993 $>\mathrm{G}$ mutation has a skewed segregation during oogenesis (Blok et al. 1997). Post-zygotic drift might explain this discrepancy (Steffann et al. 2007). Current options for women with MT-ATP6 or MT-ATP8 mutations can be oocyte donation or preimplantation genetic diagnosis (PGD), since the different heteroplasmy levels between tissues are not yet present in blastomeres (Jenuth et al. 1997; Poulton and Marchington 2002; Dean et al. 2003). The interpretation of PGD results nevertheless demands a known correlation between mutation load and clinical phenotype. In addition, caution is warranted since some pathogenic mutations could exhibit different segregation behavior (Dean et al. 2003). In case the genetic examination of an index case has revealed no mutations in both mtDNA and nDNA, prenatal diagnosis could still be possible. In Nijmegen, complex V activity can be measured spectrophotometrically in native chorionic villi, cultured chorionic cells or cultured amniotic cells if there is a clear isolated complex $\mathrm{V}$ deficiency in fibroblasts and muscle tissue (or other tissue) of the index patient (Niers et al. 2003; Rodenburg 2011).

\section{Concluding remarks and future perspectives}

Thanks to the extensive research over the last decades, nowadays much is known regarding the structure and function of the world's smallest rotary nanomotor. As mentioned briefly, most of the structure of the bovine mitochondrial enzyme has been resolved. The structure of the membrane extrinsic part of bovine ATP synthase is complete (Rees et al. 2009). The structure of the c-ring has been resolved recently (Watt et al. 2010). The structures of the membrane domain of subunit $b$, subunit $a$, and the accessory subunits e, $\mathrm{f}, \mathrm{g}$, and $\mathrm{A} 6 \mathrm{~L}$ remain to be determined (Rees et al. 2009). The mechanism of the rotary $F_{1} F_{o}$ ATP synthase has been described by Boyer (Boyer 1997). Still, understanding the enzyme fully at a molecular level will require further efforts, both experimental and theoretical (for a review, see (Junge et al. 2009)). Next to structure and function of the monocomplex, also the role of di- and oligomerization of complex $\mathrm{V}$, shaping the inner mitochondrial membrane, has been addressed in many studies both in yeast and in mammalian mitochondria (Paumard et al. 2002; Strauss et al. 2008). The role of $\mathrm{IF}_{1}$ in this process has been shown to be important (Campanella et al. 2008, 2009).

Despite this huge progress, lots of questions remain to be answered. As mentioned, the assembly of the different subunits into the holocomplex continues to be puzzling. Most of the research has been done in yeast. However, the yeast assembly process probably differs from the one in mammalian mitochondria, since there are substantial differences between higher and lower eukaryotes such as the number of $F_{o}$ subunit c-genes, ATP synthase-specific assembly factors, and factors regulating transcription of ATP synthase genes (Houstek et al. 2006). To gain further insight into the assembly of complex V, techniques like blue native and clear native PAGE, combined with incorporation and knock-down experiments of different subunits as described in (Wagner et al. 2010) could refine our current knowledge. Further, only two assembly factors, ATP11 and ATP12, are hitherto known in mammalian ATP synthase. They both have a role in $\mathrm{F}_{1}$ assembly. TMEM70 maintains normal expression levels of complex $\mathrm{V}$, and has been suggested to have a role in complex $\mathrm{V}$ biogenesis (Cizkova et al. 2008). The exact mechanism however still remains to be elucidated. Moreover, the existence of specific factors involved in mammalian $F_{o}$ formation is probable (Houstek et al. 2006). A possible approach could be to study the evolution of complex $\mathrm{V}$ subunits and complex V chaperones by comparative genomics. For example, the yeast $F_{o}$ assembly factor Atp23p has a human homolog for which, however, no involvement in ATP synthase assembly could be demonstrated (Kucharczyk et al. 2009a, b, c). Also a homology of complex $\mathrm{V}$ chaperones with other human proteins could be of interest in the search of specific assembly factors. Another intriguing fact is that to date, only one mutation has been found in a nuclear structural complex V gene (Mayr et al. 2010). It could be possible that mutations in some of the structural subunits are incompatible with life. On the other hand, given the lower frequency of complex $\mathrm{V}$ deficiency compared to the other OXPHOS deficiencies, routine screening of all nuclear structural genes is rarely implemented in a diagnostic 
setting. Whole genome or whole exome screening could counter this problem and possibly solve some of the hitherto unknown genetic defects causing complex $\mathrm{V}$ deficiency. Finally, the biggest challenge will be to find a tailored curative therapy for this patient group. Large-scale and high-throughput compound screening is needed to find a possible pharmacological approach. For mtDNA defects, gene-shifting and germline techniques are promising, but much more and thorough experimental research is needed before this can be implemented in the patient setting.

In conclusion, mitochondrial ATP synthase has been and still is a popular research topic. Thanks to sustained effort, many aspects of this intriguing protein have been elucidated. This knowledge will guide further physio(patho)logical studies, paving the way for future therapeutic interventions.

Funding This work was supported by a grant from the Prinses Beatrix Fonds [grant number OP-05-04] to AIJ and JS. The authors confirm independence from the sponsors; the content of the article has not been influenced by the sponsors.

Open Access This article is distributed under the terms of the Creative Commons Attribution Noncommercial License which permits any noncommercial use, distribution, and reproduction in any medium, provided the original author(s) and source are credited.

\section{References}

Abu-Amero KK, Bosley TM (2006) Mitochondrial abnormalities in patients with LHON-like optic neuropathies. Invest Ophthalmol Vis Sci 47:4211-4220

Ackerman SH (2002) Atp11p and Atp12p are chaperones for $F(1)$ ATPase biogenesis in mitochondria. Biochim Biophys Acta 1555:101-105

Ackerman SH, Tzagoloff A (1990) Identification of two nuclear genes (ATP11, ATP12) required for assembly of the yeast F1-ATPase. Proc Natl Acad Sci USA 87:4986-4990

Adachi K, Oiwa K, Nishizaka T et al. (2007) Coupling of rotation and catalysis in F(1)-ATPase revealed by single-molecule imaging and manipulation. Cell 130:309-321

Alexeyev MF, Venediktova N, Pastukh V, Shokolenko I, Bonilla G, Wilson GL (2008) Selective elimination of mutant mitochondrial genomes as therapeutic strategy for the treatment of NARP and MILS syndromes. Gene Ther 15:516-523

Allen RD (1995) Membrane tubulation and proton pumps. Protoplasma 189:1-8

Anderson S, Bankier AT, Barrell BG et al. (1981) Sequence and organization of the human mitochondrial genome. Nature 290:457-465

Arechaga I, Butler PJ, Walker JE (2002) Self-assembly of ATP synthase subunit $\mathrm{c}$ rings. FEBS Lett 515:189-193

Arnold I, Pfeiffer K, Neupert W, Stuart RA, Schagger H (1998) Yeast mitochondrial F1F0-ATP synthase exists as a dimer: identification of three dimer-specific subunits. EMBO J 17:7170-7178

Arnold RS, Sun CQ, Richards JC et al. (2009) Mitochondrial DNA mutation stimulates prostate cancer growth in bone stromal environment. Prostate 69:1-11
Arselin G, Giraud MF, Dautant A et al. (2003) The GxxxG motif of the transmembrane domain of subunit $\mathrm{e}$ is involved in the dimerization/oligomerization of the yeast ATP synthase complex in the mitochondrial membrane. Eur J Biochem 270:1875-1884

Baracca A, Barogi S, Carelli V, Lenaz G, Solaini G (2000) Catalytic activities of mitochondrial ATP synthase in patients with mitochondrial DNA T8993G mutation in the ATPase 6 gene encoding subunit a. J Biol Chem 275:4177-4182

Belogrudov GI (2009) Recent advances in structure-functional studies of mitochondrial factor B. J Bioenerg Biomembr 41:137-143

Belogrudov GI, Hatefi Y (2002) Factor B and the mitochondrial ATP synthase complex. J Biol Chem 277:6097-6103

Bisetto E, Picotti P, Giorgio V, Alverdi V, Mavelli I, Lippe G (2008) Functional and stoichiometric analysis of subunit $\mathrm{e}$ in bovine heart mitochondrial $\mathrm{F}(0) \mathrm{F}(1)$ ATP synthase. J Bioenerg Biomembr 40:257-267

Blok RB, Gook DA, Thorburn DR, Dahl HH (1997) Skewed segregation of the mtDNA nt $8993(\mathrm{~T}->\mathrm{G})$ mutation in human oocytes. Am J Hum Genet 60:1495-1501

Boyer PD (1975) A model for conformational coupling of membrane potential and proton translocation to ATP synthesis and to active transport. FEBS Lett 58:1-6

Boyer PD (1997) The ATP synthase-a splendid molecular machine. Annu Rev Biochem 66:717-749

Boyer PD, Kohlbrenner WE (1981) The present status of the bindingchange mechanism and its relation to ATP formation by chloroplasts. In: Selman BR, Selman-Peimer S (eds) Energy coupling in photosynthesis. Elsevier, Amsterdam, pp 231-240

Brown DT, Herbert M, Lamb VK et al. (2006) Transmission of mitochondrial DNA disorders: possibilities for the future. Lancet 368:87-89

Cabezon E, Butler PJ, Runswick MJ, Walker JE (2000) Modulation of the oligomerization state of the bovine F1-ATPase inhibitor protein, IF1, by pH. J Biol Chem 275:25460-25464

Cabezon E, Runswick MJ, Leslie AG, Walker JE (2001) The structure of bovine $\mathrm{IF}(1)$, the regulatory subunit of mitochondrial F-ATPase. EMBO J 20:6990-6996

Cabezon E, Montgomery MG, Leslie AG, Walker JE (2003) The structure of bovine F1-ATPase in complex with its regulatory protein IF1. Nat Struct Biol 10:744-750

Calvo S, Jain M, Xie X et al. (2006) Systematic identification of human mitochondrial disease genes through integrative genomics. Nat Genet 38:576-582

Cameron JM, Levandovskiy V, Mackay N et al. (2011) Complex V TMEM70 deficiency results in mitochondrial nucleoid disorganization. Mitochondrion 11:191-199

Campanella M, Casswell E, Chong S et al. (2008) Regulation of mitochondrial structure and function by the F1Fo-ATPase inhibitor protein, IF1. Cell Metab 8:13-25

Campanella M, Parker N, Tan CH, Hall AM, Duchen MR (2009) IF (1): setting the pace of the $\mathrm{F}(1) \mathrm{F}(\mathrm{o})$-ATP synthase. Trends Biochem Sci 34:343-350

Capaldi RA, Aggeler R, Turina P, Wilkens S (1994) Coupling between catalytic sites and the proton channel in F1F0-type ATPases. Trends Biochem Sci 19:284-289

Carelli V, Baracca A, Barogi S et al. (2002) Biochemical-clinical correlation in patients with different loads of the mitochondrial DNA T8993G mutation. Arch Neurol 59:264-270

Carrozzo R, Tessa A, Vazquez-Memije ME et al. (2001) The T9176G mtDNA mutation severely affects ATP production and results in Leigh syndrome. Neurology 56:687-690

Childs AM, Hutchin T, Pysden K et al. (2007) Variable phenotype including Leigh syndrome with a 9185T $>\mathrm{C}$ mutation in the MTATP6 gene. Neuropediatrics 38:313-316

Chinnery P, Majamaa K, Turnbull D, Thorburn D (2006) Treatment for mitochondrial disorders. Cochrane Database Syst Rev: CD004426. 
Cizkova A, Stranecky V, Mayr JA et al. (2008) TMEM70 mutations cause isolated ATP synthase deficiency and neonatal mitochondrial encephalocardiomyopathy. Nat Genet 40:1288-1290

Cooperstein SJ, Lazarow A (1951) A microspectrophotometric method for the determination of cytochrome oxidase. J Biol Chem 189:665-670

Cortes-Hernandez P, Vazquez-Memije ME, Garcia JJ (2007) ATP6 homoplasmic mutations inhibit and destabilize the human F1F0ATP synthase without preventing enzyme assembly and oligomerization. J Biol Chem 282:1051-1058

Cox GB, Jans DA, Fimmel AL, Gibson F, Hatch L (1984) Hypothesis. The mechanism of ATP synthase. Conformational change by rotation of the beta-subunit. Biochim Biophys Acta 768:201-208

Craven L, Tuppen HA, Greggains GD et al. (2010) Pronuclear transfer in human embryos to prevent transmission of mitochondrial DNA disease. Nature 465:82-85

Cross RL, Muller V (2004) The evolution of A-, F-, and V-type ATP synthases and ATPases: reversals in function and changes in the H+/ATP coupling ratio. FEBS Lett 576:1-4

Dahl HH, Thorburn DR, White SL (2000) Towards reliable prenatal diagnosis of mtDNA point mutations: studies of nt8993 mutations in oocytes, fetal tissues, children and adults. Hum Reprod 15(Suppl 2):246-255

D'Aurelio M, Vives-Bauza C, Davidson MM, Manfredi G (2010) Mitochondrial DNA background modifies the bioenergetics of NARP/MILS ATP6 mutant cells. Hum Mol Genet 19:374-386

De Meirleir L, Seneca S, Lissens W, Schoentjes E, Desprechins B (1995) Bilateral striatal necrosis with a novel point mutation in the mitochondrial ATPase 6 gene. Pediatr Neurol 13:242-246

De Meirleir L, Seneca S, Lissens W et al. (2004) Respiratory chain complex $\mathrm{V}$ deficiency due to a mutation in the assembly gene ATP12. J Med Genet 41:120-124

de Vries DD, van Engelen BG, Gabreels FJ, Ruitenbeek W, van Oost BA (1993) A second missense mutation in the mitochondrial ATPase 6 gene in Leigh's syndrome. Ann Neurol 34:410-412

Dean NL, Battersby BJ, Ao A et al. (2003) Prospect of preimplantation genetic diagnosis for heritable mitochondrial DNA diseases. Mol Hum Reprod 9:631-638

Debray FG, Lambert M, Lortie A, Vanasse M, Mitchell GA (2007) Long-term outcome of Leigh syndrome caused by the NARPT8993C mtDNA mutation. Am J Med Genet A 143A:2046-2051

Devenish RJ, Prescott M, Boyle GM, Nagley P (2000) The oligomycin axis of mitochondrial ATP synthase: OSCP and the proton channel. J Bioenerg Biomembr 32:507-515

Devenish RJ, Prescott M, Rodgers AJ (2008) The structure and function of mitochondrial F1F0-ATP synthases. Int Rev Cell Mol Biol 267:1-58

Dickson VK, Silvester JA, Fearnley IM, Leslie AG, Walker JE (2006) On the structure of the stator of the mitochondrial ATP synthase. EMBO J 25:2911-2918

DiMauro S, Hirano M, Schon EA (2006) Approaches to the treatment of mitochondrial diseases. Muscle Nerve 34:265-283

Dionisi-Vici C, Seneca S, Zeviani M et al. (1998) Fulminant Leigh syndrome and sudden unexpected death in a family with the T9176C mutation of the mitochondrial ATPase 6 gene. J Inherit Metab Dis 21:2-8

Garcia JJ, Ogilvie I, Robinson BH, Capaldi RA (2000) Structure, functioning, and assembly of the ATP synthase in cells from patients with the T8993G mitochondrial DNA mutation. Comparison with the enzyme in Rho(0) cells completely lacking mtdna. J Biol Chem 275:11075-11081

Gibbons C, Montgomery MG, Leslie AG, Walker JE (2000) The structure of the central stalk in bovine F(1)-ATPase at $2.4 \mathrm{~A}$ resolution. Nat Struct Biol 7:1055-1061

Havlickova V, Kaplanova V, Nuskova H, Drahota Z, Houstek J (2010) Knockdown of F1 epsilon subunit decreases mitochondrial content of ATP synthase and leads to accumulation of subunit c. Biochim Biophys Acta 1797:1124-1129

Hejzlarova K, Tesarova M, Vrbacka-Cizkova A et al. (2011) Expression and processing of the TMEM70 protein. Biochim Biophys Acta 1807:144-149

Holt IJ, Harding AE, Petty RK, Morgan-Hughes JA (1990) A new mitochondrial disease associated with mitochondrial DNA heteroplasmy. Am J Hum Genet 46:428-433

Honzik T, Tesarova M, Mayr JA et al. (2010) Mitochondrial encephalocardio-myopathy with early neonatal onset due to TMEM70 mutation. Arch Dis Child 95:296-301

Houstek J, Pickova A, Vojtiskova A, Mracek T, Pecina P, Jesina P (2006) Mitochondrial diseases and genetic defects of ATP synthase. Biochim Biophys Acta 1757:1400-1405

Hung PC, Wang HS (2007) A previously undescribed leukodystrophy in Leigh syndrome associated with $\mathrm{T} 9176 \mathrm{C}$ mutation of the mitochondrial ATPase 6 gene. Dev Med Child Neurol 49:65-67

Iino R, Hasegawa R, Tabata KV, Noji H (2009) Mechanism of inhibition by C-terminal alpha-helices of the epsilon subunit of Escherichia coli FoF1-ATP synthase. J Biol Chem 284:1745717464

Janssen AJ, Smeitink JA, van den Heuvel LP (2003) Some practical aspects of providing a diagnostic service for respiratory chain defects. Ann Clin Biochem 40:3-8

Janssen AJ, Trijbels FJ, Sengers RC et al. (2006) Measurement of the energy-generating capacity of human muscle mitochondria: diagnostic procedure and application to human pathology. Clin Chem 52:860-871

Jenuth JP, Peterson AC, Shoubridge EA (1997) Tissue-specific selection for different mtDNA genotypes in heteroplasmic mice. Nat Genet 16:93-95

Jonckheere AI, Hogeveen M, Nijtmans LG et al. (2008) A novel mitochondrial ATP8 gene mutation in a patient with apical hypertrophic cardiomyopathy and neuropathy. J Med Genet 45:129-133

Jonckheere AI, Huigsloot M, Janssen AJ, Kappen AJ, Smeitink JA, Rodenburg RJ (2010) High-throughput assay to measure oxygen consumption in digitonin-permeabilized cells of patients with mitochondrial disorders. Clin Chem 56:424-431

Junge W, Sielaff H, Engelbrecht S (2009) Torque generation and elastic power transmission in the rotary $\mathrm{F}(\mathrm{O}) \mathrm{F}(1)$-ATPase. Nature 459:364-370

Kirby DM, Thorburn DR, Turnbull DM, Taylor RW (2007) Biochemical assays of respiratory chain complex activity. Methods Cell Biol 80:93-119

Koene S, Smeitink J (2009) Mitochondrial medicine: entering the era of treatment. J Intern Med 265:193-209

Koene S, Smeitink J (2010) Metabolic manipulators: a well founded strategy to combat mitochondrial dysfunction. J Inherit Metab Dis

Krause F, Reifschneider NH, Goto S, Dencher NA (2005) Active oligomeric ATP synthases in mammalian mitochondria. Biochem Biophys Res Commun 329:583-590

Kucharczyk R, Rak M, di Rago JP (2009a) Biochemical consequences in yeast of the human mitochondrial DNA $8993 \mathrm{~T}>\mathrm{C}$ mutation in the ATPase6 gene found in NARP/MILS patients. Biochim Biophys Acta 1793:817-824

Kucharczyk R, Salin B, di Rago JP (2009b) Introducing the human Leigh syndrome mutation T9176G into Saccharomyces cerevisiae mitochondrial DNA leads to severe defects in the incorporation of Atp6p into the ATP synthase and in the mitochondrial morphology. Hum Mol Genet 18:2889-2898

Kucharczyk R, Zick M, Bietenhader M et al. (2009c) Mitochondrial ATP synthase disorders: molecular mechanisms and the quest for curative therapeutic approaches. Biochim Biophys Acta 1793:186-199

Kucharczyk R, Ezkurdia N, Couplan E et al. (2010) Consequences of the pathogenic T9176C mutation of human mitochondrial DNA 
on yeast mitochondrial ATP synthase. Biochim Biophys Acta 1797:1105-1112

La Morgia C, Achilli A, Iommarini L et al. (2008) Rare mtDNA variants in Leber hereditary optic neuropathy families with recurrence of myoclonus. Neurology 70:762-770

Lamminen T, Majander A, Juvonen V et al. (1995) A mitochondrial mutation at nt 9101 in the ATP synthase 6 gene associated with deficient oxidative phosphorylation in a family with Leber hereditary optic neuroretinopathy. Am J Hum Genet 56:12381240

Lee LK, Stewart AG, Donohoe M, Bernal RA, Stock D (2010) The structure of the peripheral stalk of Thermus thermophilus H+-ATPase/ synthase. Nat Struct Mol Biol 17:373-378

Lefebvre-Legendre L, Salin B, Schaeffer J et al. (2005) Failure to assemble the alpha 3 beta 3 subcomplex of the ATP synthase leads to accumulation of the alpha and beta subunits within inclusion bodies and the loss of mitochondrial cristae in Saccharomyces cerevisiae. J Biol Chem 280:18386-18392

Lenaz G, Baracca A, Carelli V, D'Aurelio M, Sgarbi G, Solaini G (2004) Bioenergetics of mitochondrial diseases associated with mtDNA mutations. Biochim Biophys Acta 1658:89-94

Manfredi G, Gupta N, Vazquez-Memije ME et al. (1999) Oligomycin induces a decrease in the cellular content of a pathogenic mutation in the human mitochondrial ATPase 6 gene. J Biol Chem 274:9386-9391

Manfredi G, Fu J, Ojaimi J et al. (2002) Rescue of a deficiency in ATP synthesis by transfer of MTATP6, a mitochondrial DNA-encoded gene, to the nucleus. Nat Genet 30:394-399

Matsuno-Yagi A, Yagi T, Hatefi Y (1985) Studies on the mechanism of oxidative phosphorylation: effects of specific F0 modifiers on ligand-induced conformation changes of F1. Proc Natl Acad Sci USA 82:7550-7554

Mattiazzi M, Vijayvergiya C, Gajewski CD et al. (2004) The mtDNA T8993G (NARP) mutation results in an impairment of oxidative phosphorylation that can be improved by antioxidants. Hum Mol Genet 13:869-879

Mayr JA, Havlickova V, Zimmermann F et al. (2010) Mitochondrial ATP synthase deficiency due to a mutation in the ATP5E gene for the F1 epsilon subunit. Hum Mol Genet 19:3430-3439

Meulemans A, Seneca S, Pribyl T et al. (2010) Defining the pathogenesis of the human Atp12p W94R mutation using a Saccharomyces cerevisiae yeast model. J Biol Chem 285:40994109

Meyer B, Wittig I, Trifilieff E, Karas M, Schagger H (2007) Identification of two proteins associated with mammalian ATP synthase. Mol Cell Proteomics 6:1690-1699

Mkaouar-Rebai E, Chaari W, Younes S, Bousoffara R, Sfar MT, Fakhfakh F (2009) Maternally inherited Leigh syndrome: T8993G mutation in a Tunisian family. Pediatr Neurol 40:437442

Mkaouar-Rebai E, Kammoun F, Chamkha I et al. (2010) A de novo mutation in the adenosine triphosphatase (ATPase) 8 gene in a patient with mitochondrial disorder. J Child Neurol 25:770-775

Mnatsakanyan N, Hook JA, Quisenberry L, Weber J (2009) ATP synthase with its gamma subunit reduced to the N-terminal helix can still catalyze ATP synthesis. J Biol Chem 284:26519-26525

Morava E, Rodenburg RJ, Hol F et al. (2006) Clinical and biochemical characteristics in patients with a high mutant load of the mitochondrial T8993G/C mutations. Am J Med Genet A 140:863-868

Moslemi AR, Darin N, Tulinius M, Oldfors A, Holme E (2005) Two new mutations in the MTATP6 gene associated with Leigh syndrome. Neuropediatrics 36:314-318

Niers L, van den Heuvel L, Trijbels F, Sengers R, Smeitink J (2003) Prerequisites and strategies for prenatal diagnosis of respiratory chain deficiency in chorionic villi. J Inherit Metab Dis 26:647-658
Nijtmans LG, Klement P, Houstek J, van den Bogert C (1995) Assembly of mitochondrial ATP synthase in cultured human cells: implications for mitochondrial diseases. Biochim Biophys Acta 1272:190-198

Nijtmans LG, Henderson NS, Holt IJ (2002) Blue Native electrophoresis to study mitochondrial and other protein complexes. Methods 26:327-334

Ohsakaya S, Fujikawa M, Hisabori T, Yoshida M (2011) Knockdown of DAPIT (diabetes-associated protein in insulin-sensitive tissue) results in loss of ATP synthase in mitochondria. J Biol Chem

Ojaimi J, Pan J, Santra S, Snell WJ, Schon EA (2002) An algal nucleus-encoded subunit of mitochondrial ATP synthase rescues a defect in the analogous human mitochondrial-encoded subunit. Mol Biol Cell 13:3836-3844

Pallotti F, Baracca A, Hernandez-Rosa E et al. (2004) Biochemical analysis of respiratory function in cybrid cell lines harbouring mitochondrial DNA mutations. Biochem J 384:287-293

Paumard P, Vaillier J, Coulary B et al. (2002) The ATP synthase is involved in generating mitochondrial cristae morphology. EMBO J 21:221-230

Penefsky HS (1985) Mechanism of inhibition of mitochondrial adenosine triphosphatase by dicyclohexylcarbodiimide and oligomycin: relationship to ATP synthesis. Proc Natl Acad Sci USA 82:1589-1593

Petros JA, Baumann AK, Ruiz-Pesini E et al. (2005) mtDNA mutations increase tumorigenicity in prostate cancer. Proc Natl Acad Sci USA 102:719-724

Poulton J, Marchington DR (2002) Segregation of mitochondrial DNA (mtDNA) in human oocytes and in animal models of mtDNA disease: clinical implications. Reproduction 123:751-755

Povalko N, Zakharova E, Rudenskaia G et al. (2005) A new sequence variant in mitochondrial DNA associated with high penetrance of Russian Leber hereditary optic neuropathy. Mitochondrion 5:194-199

Pullman ME, Monroy GC (1963) A naturally occurring inhibitor of mitochondrial adenosine triphosphatase. J Biol Chem 238:37623769

Rabl R, Soubannier V, Scholz R et al. (2009) Formation of cristae and crista junctions in mitochondria depends on antagonism between Fcj1 and Su e/g. J Cell Biol 185:1047-1063

Rak M, Tzagoloff A (2009) F1-dependent translation of mitochondrially encoded Atp6p and Atp8p subunits of yeast ATP synthase. Proc Natl Acad Sci USA 106:18509-18514

Rak M, Tetaud E, Duvezin-Caubet S et al. (2007a) A yeast model of the neurogenic ataxia retinitis pigmentosa (NARP) T8993G mutation in the mitochondrial ATP synthase- 6 gene. J Biol Chem 282:34039-34047

Rak M, Tetaud E, Godard F et al. (2007b) Yeast cells lacking the mitochondrial gene encoding the ATP synthase subunit 6 exhibit a selective loss of complex IV and unusual mitochondrial morphology. J Biol Chem 282:10853-10864

Rak M, Zeng X, Briere JJ, Tzagoloff A (2009) Assembly of F0 in Saccharomyces cerevisiae. Biochim Biophys Acta 1793:108-116

Rak M, Gokova S, Tzagoloff A (2011) Modular assembly of yeast mitochondrial ATP synthase. EMBO J 30:920-930

Rees DM, Leslie AG, Walker JE (2009) The structure of the membrane extrinsic region of bovine ATP synthase. Proc Natl Acad Sci USA 106:21597-21601

Rodenburg RJ (2011) Biochemical diagnosis of mitochondrial disorders. J Inherit Metab Dis 34:283-292

Sanchez-Cenizo L, Formentini L, Aldea M et al. (2010) Up-regulation of the ATPase inhibitory factor 1 (IF1) of the mitochondrial $\mathrm{H}+$-ATP synthase in human tumors mediates the metabolic shift of cancer cells to a Warburg phenotype. J Biol Chem 285:25308-25313

Sato A, Kono T, Nakada K et al. (2005) Gene therapy for progeny of mito-mice carrying pathogenic mtDNA by nuclear transplantation. Proc Natl Acad Sci USA 102:16765-16770 
Schagger H, Pfeiffer K (2000) Supercomplexes in the respiratory chains of yeast and mammalian mitochondria. EMBO J 19:1777-1783

Schagger H, von Jagow G (1991) Blue native electrophoresis for isolation of membrane protein complexes in enzymatically active form. Anal Biochem 199:223-231

Schapira AH (2006) Mitochondrial disease. Lancet 368:70-82

Schwimmer C, Lefebvre-Legendre L, Rak M et al. (2005) Increasing mitochondrial substrate-level phosphorylation can rescue respiratory growth of an ATP synthase-deficient yeast. J Biol Chem 280:30751-30759

Seneca S, Abramowicz M, Lissens W, Muller MF, Vamos E, de Meirleir L (1996) A mitochondrial DNA microdeletion in a newborn girl with transient lactic acidosis. J Inherit Metab Dis 19:115-118

Sgarbi G, Baracca A, Lenaz G, Valentino LM, Carelli V, Solaini G (2006) Inefficient coupling between proton transport and ATP synthesis may be the pathogenic mechanism for NARP and Leigh syndrome resulting from the T8993G mutation in mtDNA. Biochem J 395:493-500

Sgarbi G, Casalena GA, Baracca A, Lenaz G, DiMauro S, Solaini G (2009) Human NARP mitochondrial mutation metabolism corrected with alpha-ketoglutarate/aspartate: a potential new therapy. Arch Neurol 66:951-957

Shchelochkov OA, Li FY, Wang J et al. (2010) Milder clinical course of Type IV 3-methylglutaconic aciduria due to a novel mutation in TMEM70. Mol Genet Metab 101:282-285

Sikorska M, Sandhu JK, Simon DK et al. (2009) Identification of ataxiaassociated mtDNA mutations (m.4052T $>\mathrm{C}$ and $\mathrm{m} .9035 \mathrm{~T}>\mathrm{C})$ and evaluation of their pathogenicity in transmitochondrial cybrids. Muscle Nerve 40:381-394

Spiegel R, Khayat M, Shalev SA et al. (2011) TMEM70 mutations are a common cause of nuclear encoded ATP synthase assembly defect: further delineation of a new syndrome. J Med Genet 48:177-182

Steffann J, Gigarel N, Corcos J et al. (2007) Stability of the m.8993T->G mtDNA mutation load during human embryofetal development has implications for the feasibility of prenatal diagnosis in NARP syndrome. J Med Genet 44:664-669

Stephens AN, Nagley P, Devenish RJ (2003) Each yeast mitochondrial F1F0-ATP synthase complex contains a single copy of subunit 8 . Biochim Biophys Acta 1607:181-189

Stock D, Leslie AG, Walker JE (1999) Molecular architecture of the rotary motor in ATP synthase. Science 286:1700-1705

Strauss M, Hofhaus G, Schroder RR, Kuhlbrandt W (2008) Dimer ribbons of ATP synthase shape the inner mitochondrial membrane. EMBO J 27:1154-1160

Tachibana M, Sparman M, Sritanaudomchai H et al. (2009) Mitochondrial gene replacement in primate offspring and embryonic stem cells. Nature 461:367-372

Tanaka M, Borgeld HJ, Zhang J et al. (2002) Gene therapy for mitochondrial disease by delivering restriction endonuclease SmaI into mitochondria. J Biomed Sci 9:534-541

Tatuch Y, Robinson BH (1993) The mitochondrial DNA mutation at 8993 associated with NARP slows the rate of ATP synthesis in isolated lymphoblast mitochondria. Biochem Biophys Res Commun 192:124-128

Temperley RJ, Seneca SH, Tonska K et al. (2003) Investigation of a pathogenic mtDNA microdeletion reveals a translation-dependent deadenylation decay pathway in human mitochondria. Hum Mol Genet 12:2341-2348

Thomas D, Bron P, Weimann T et al. (2008) Supramolecular organization of the yeast F1Fo-ATP synthase. Biol Cell 100:591-601
Thyagarajan D, Shanske S, Vazquez-Memije M, De Vivo D, DiMauro S (1995) A novel mitochondrial ATPase 6 point mutation in familial bilateral striatal necrosis. Ann Neurol 38:468-472

Toei M, Saum R, Forgac M (2010) Regulation and isoform function of the V-ATPases. Biochemistry 49:4715-4723

Trounce I, Neill S, Wallace DC (1994) Cytoplasmic transfer of the mtDNA nt 8993T->G (ATP6) point mutation associated with Leigh syndrome into mtDNA-less cells demonstrates cosegregation with a decrease in state III respiration and ADP/O ratio. Proc Natl Acad Sci USA 91:8334-8338

van der Walt JM, Nicodemus KK, Martin ER et al. (2003) Mitochondrial polymorphisms significantly reduce the risk of Parkinson disease. Am J Hum Genet 72:804-811

Van Heeke G, Deforce L, Schnizer RA et al. (1993) Recombinant bovine heart mitochondrial F1-ATPase inhibitor protein: overproduction in Escherichia coli, purification, and structural studies. Biochemistry 32:10140-10149

Vazquez-Memije ME, Shanske S, Santorelli FM, Kranz-Eble P, DeVivo DC, DiMauro S (1998) Comparative biochemical studies of ATPases in cells from patients with the T8993G or T8993C mitochondrial DNA mutations. J Inherit Metab Dis 21:829-836

Velours J, Arselin G (2000) The Saccharomyces cerevisiae ATP synthase. J Bioenerg Biomembr 32:383-390

Verny C, Guegen N, Desquiret V et al. (2011) Hereditary spastic paraplegia-like disorder due to a mitochondrial ATP6 gene point mutation. Mitochondrion 11:70-75

Vives-Bauza C, Magrane J, Andreu AL, Manfredi G (2010) Novel role of ATPase subunit $\mathrm{C}$ targeting peptides beyond mitochondrial protein import. Mol Biol Cell 21:131-139

Wagner K, Perschil I, Fichter CD, van der Laan M (2010) Stepwise assembly of dimeric $\mathrm{F}(1) \mathrm{F}(\mathrm{o})$-ATP synthase in mitochondria involves the small F(o)-subunits k and i. Mol Biol Cell 21:1494-1504

Walker JE, Dickson VK (2006) The peripheral stalk of the mitochondrial ATP synthase. Biochim Biophys Acta 1757:286-296

Wallace DC (2005) A mitochondrial paradigm of metabolic and degenerative diseases, aging, and cancer: a dawn for evolutionary medicine. Annu Rev Genet 39:359-407

Wang ZG, Sheluho D, Gatti DL, Ackerman SH (2000) The alpha-subunit of the mitochondrial $F(1)$ ATPase interacts directly with the assembly factor Atp12p. EMBO J 19:1486-1493

Ware SM, El-Hassan N, Kahler SG et al. (2009) Infantile cardiomyopathy caused by a mutation in the overlapping region of mitochondrial ATPase 6 and 8 genes. J Med Genet 46:308-314

Watt IN, Montgomery MG, Runswick MJ, Leslie AG, Walker JE (2010) Bioenergetic cost of making an adenosine triphosphate molecule in animal mitochondria. Proc Natl Acad Sci USA 107:16823-16827

Wittig I, Schagger H (2005) Advantages and limitations of clear-native PAGE. Proteomics 5:4338-4346

Wittig I, Schagger H (2008) Structural organization of mitochondrial ATP synthase. Biochim Biophys Acta 1777:592-598

Wittig I, Schagger H (2009) Supramolecular organization of ATP synthase and respiratory chain in mitochondrial membranes. Biochim Biophys Acta 1787:672-680

Wittig I, Meyer B, Heide H et al. (2010) Assembly and oligomerization of human ATP synthase lacking mitochondrial subunits a and A6L. Biochim Biophys Acta 1797:1004-1011

Zeviani M, Di Donato S (2004) Mitochondrial disorders. Brain 127:2153-2172

Zick M, Rabl R, Reichert AS (2009) Cristae formation-linking ultrastructure and function of mitochondria. Biochim Biophys Acta 1793:5-19 